\title{
The Sociology of Near Misses: A Methodological Framework For Studying Events That 'Almost HAPPENED'
}

\author{
GARRY GRAY
}

\begin{abstract}
Near miss research shifts the conceptual focus away from the negative outcome of events to the study of everyday close calls and represents an alternative pathway into knowledge production. The discipline of sociology is well suited for the study of near misses given its focus on social context, social meanings, and analyzing social interactions and patterns of group behaviour. This article discusses the challenges that researchers will face when conducting near miss research as well as different near miss data collection strategies. A comparison of two unique near miss data sets, on the same population, is also provided in order to illustrate that different methodologies capture different types of near miss information. Near misses represent an untapped area of research not yet fully explored by sociologists and social scientists.
\end{abstract}

Keywords: Near Misses; Methodology; Data Collection; Accidents; Uncertainty; Risk

Résumé. La recherche sur les « presque accidents » permet de déplacer le cadre conceptuel, habituellement centré sur les conséquences négatives des événements, à l'étude des accidents évités de justesse qui font partie de la vie quotidienne. Un tel déplacement représente ainsi une voie alternative de production de connaissances. Étant donné l'importance donnée au contexte social, à la contruction du sens, et aux interactions sociales et comportements de groupe, la discipline sociologique se prête bien à l'étude des presque accidents. Cet article discute des défis rencontrés au cours de la recherche sur les preque accidents, ainsi que des différentes stratégies de collecte de données possibles. Les différentes méthodologies seront illustrées par le biais d'une comparaison entre deux bases de données portant sur la même population, qui capturent différents types de données sur les presque accidents. Les presque accidents représentent un domaine de recherche en émergence qui demande à être exploré plus à fond par les chercheurs et chercheuses en sciences sociales.

Mots clés: Presque accidents; Méthodologie; Collecte de données; Accidents; Incertitude; Risque 


\section{INTRODUCTION}

Non ear miss events happen everywhere: at work, while driving, when walking across the street, inside hospitals, in the skies between jets, and even during social encounters. For many of the topics that scholars have traditionally been interested in conducting research on there are corresponding near misses occurring. These incidents often result from failures of communication and occur across various patterns of social interaction. Yet, despite the high frequency of such near miss phenomena most researchers still wait for a situation to result in a negative/ adverse outcome before beginning analyses of the event. As a result, near misses represent an untapped area of social science research not yet fully explored by sociologists. In this article, I put forth the position that a shift away from the sole conceptual focus on negative outcomes of events to the inclusion of studies on everyday near misses is needed. The discipline of sociology is well suited for the study of near misses given its focus on social context, social meanings, and analyzing social interactions and patterns of group behaviour. The implications of near misses and the need to study them has been highlighted in other fields such as health care (Clarke et al., 2002), gambling addiction (Parke and Griffiths, 2004), motor vehicle driving (Powell et al., 2007), job stress (Goldenhar et al., 2003), and occupational safety (Gray, 2002).

By studying events that almost happened, social scientists have the potential to gain a fuller understanding of any given phenomenon. In addition, issues of hindsight and retrospection become transparent when we examine our reactions to events that result in harm and negative outcomes. However, at present, a near miss methodology is not available for sociologists and other researchers to draw upon in the study of near miss events. This article seeks to move toward and help build a near miss research framework by first engaging with the methodological issues and challenges that researchers will face when conducting near miss research. For instance, how does a researcher respond when asked why they are studying a specific type of near miss? If they are important then why are they often downplayed in research and among the general public? To begin, the historical lack of recognition of near miss events is primarily due to the absence of a negative outcome. When near miss events do garner public attention they are generally sensational near misses that are dramatic and the potential for devastation is easily recognizable (i.e., aviation near miss events and near miss disasters). The more commonly occurring and mundane near misses are generally ignored by researchers in general and sociologists in particular. 
The historical lack of research interest in near misses has also stemmed, in part, from the methodological assumption that if near miss events are similar to events that result in a negative outcome then why not just continue to study large-scale events; documentation and data are more likely to exist on events that actually do produce a negative outcome. The counter-argument to this line of reasoning is that by drawing attention only to events that have a fatal or injurious health outcome, we neglect the study of serious everyday situations that form the more common lived experience of individuals in both the public and private domain. For example, despite the high rates of fatalities that occur each year on the road and in the workplace, most drivers and employees are not severely injured or killed. On the other hand, workplace and motor vehicle near misses are so common that employees not only have to live with them on a daily basis (and drivers to a lesser degree of frequency), but such incidents also tend to become regarded over time as a normal part of work and the routine of driving. The details and information surrounding the social context of these near misses are rarely recorded thus limiting the opportunity to learn from such events.

Near miss events, when recorded, not only have consequences that can be measured quantitatively, but also provide qualitative data on less visible processes and rationalizations across a variety of public and private social settings. These latter insights provide opportunities to learn about the process of events and decision-making surrounding events that do happen. An example of this is when a near miss or avoided violence becomes interpersonal violence or when repeated close calls eventually result in an injury or fatality. Similar to routine activities theory (Cohen and Felson, 1979), there is much to be gained by learning about everyday routine situations embedded in our environmental and social contexts. By focusing on near misses, there is potential to further decrease opportunities that result in harm as well as contribute to both improved public safety and future crime prevention (Gray, 2008).

The remainder of the article will be organized in the following manner. I first discuss the challenges of observing near misses and then turn to an analysis of how our choices of data collection affect the type of near miss data that we ultimately observe. I then provide a comparison of two near miss data sets on the same population (an ethnography of a factory and a survey of the same factory) in order to illustrate that different methods may capture different types of events that almost happened in the same social setting (e.g., sensational near misses vs. mundane near misses). I conclude with future directions in near miss research as well as new ways to conceptualize what constitutes a near miss. 


\section{The Challenges of Observing Near Misses}

The study of near miss events will present a methodological challenge to researchers who traditionally base their discussions and research designs on negative outcomes (i.e., sick or not sick, hit by a car or not hit by a car, a workplace accident or no workplace accident). Here, the event that did not happen (the lack of sickness, not being hit by car, and no workplace accident) would normally be coded as 'O'; the events that do happen (sickness, hit by a car, workplace accident) become coded as ' 1 '. Therefore, what is lost (or designed away) in traditional research focused on negative outcomes is the potential variation between 0 and 1. Drawing on the near miss research perspective, a near miss event would be more accurately conceptualized as a 0.9 (almost 1$)$. Yet, under current research designs, near miss events are routinely ignored, not thought about, and/ or indirectly coded as 0 (along with all the other cases that did not happen regardless of whether a near miss event took place). The near miss approach therefore makes problematic the methodological operationalization of certain outcomes in traditional research. However, at the same time, drawing upon near misses can increase the statistical strength of studies because near misses occur at higher frequencies than the same events resulting in negative outcomes (Wright and van der Schaff, 2004; Kaplan, 2005).

The following general definition will provide a useful guide for studies drawing on the near miss research perspective put forth here: a near miss event is a situation that almost happened whereby the outcome of the event did not result in illness, injury, harm and/or any other negative outcome. The most important distinction between a near miss event and its corresponding phenomena is the outcome. Definitions of particular near miss events should therefore make explicit the lack of a negative outcome. Under the majority of near miss circumstances, it is only the absence of the negative outcome that separate near misses from their corresponding events with negative outcomes (Van der Schaff, 1991; Laughery and Vaubel, 1993). ${ }^{1}$

Studies of near misses should make explicit whether they are conceptualizing near miss events as a process (more suited for qualitative research), discrete outcome (quantitative research) or as both (mixed methods). In some sectors, such as medicine and health care, the value of addressing near misses is that they serve as learning tools in prevention (Barach and Small, 2000; Lundy et al., 2007). In addition, depending on

1. Although near misses involve nearly missing a negative outcome, it's logically consistent to presume that there might also be different types of near misses for positive outcomes. 
the particular near miss event, it would be useful to discuss the impact of the event. For example, is the near miss implicitly being conceptualized as a positive or negative event? In many workplaces, a near miss is often regarded by employees as positive (a matter of luck) because the near miss did not result in a negative health outcome. Here, near misses are deemed helpful in alerting an organization to potential problems. Some sectors though attempt to eliminate any near misses from occurring because the consequences of a near miss eventually becoming a negative outcome could be devastating (i.e., space shuttle disasters, nuclear power plant accidents).

\section{Reporting Near Misses}

There are a set of additional factors to consider depending upon the setting or location of the near miss event. For example, in a study of pedestrian cross-walk near misses, the primary concern is collecting near miss data from individuals in public spaces. Although it is an offence to leave the scene of a car accident involving a pedestrian (a 'hit and run'), it is not an offence to leave the scene of a pedestrian near miss incident (a 'miss and run'). Therefore, near miss research in public spaces will face the common challenges of obtaining data from difficult-to-reach populations (Watters and Biernacki, 1989). In contrast to public near misses, inside the workplace a population is in a set location and due to the constraints of employment relationships is unlikely to disappear from the research site. However, a major obstacle in the collection of organizational near miss data has been the issue of employees worrying that they will be punished for reporting near misses if the near miss resulted from an error or the lack of compliance with a rule (Kaplan, 2005; Gray, 2006, 2011; Conerly, 2007).

In addition, differences exist in the perception of risk in near misses and this has implications for the study of all near misses. For instance, when a near miss event occurs, individuals routinely develop their own interpretation of the situation. In workplace near misses, one employee may continue to work seemingly unbothered while another worker may believe the situation is too dangerous. Near miss events are therefore difficult to research because the classification of near misses is often a subjective process. In other words, how close or near must an event be to be classified as a near miss? Furthermore, for near misses to be recognized a person must decide to make a report and/or file a complaint on an event that 'almost happened' and where there is no distinct negative outcome. Perceptions of how near a situation is to potential injury may change over time and with repeated exposure to dangerous situations. 
In other words, there is a normalization process in both the recognition of and experiences with near miss events. Human judgement and uncertainty may also play a role in individual decision-making about what is and what is not a 'near miss'.

While individual responsibility is often emphasized in near miss reporting in sectors such as aviation, in most organizations these events are never recorded. Workers also routinely withhold near miss data information for fear of discipline (Vincent, 1999). As Collinson (1999) observed in his study of North Sea oil workers, employees in the lower end of job security, such as contract and temporary workers, limit reporting in order to continue contractual employment. In addition, if the near miss resulted from a rule violation then the threat of discipline, perceived or real, is a major deterrent in the collection of near miss information. Near miss safety campaigns, if administrated in atmospheres of trust, may assist in disrupting the non-reporting normalization process and serve to increase near miss awareness in everyday settings.

\section{Issues of Memory and Emotion}

Near miss research also needs to address issues of memory and emotion as it relates to specific near miss events. In particular, researchers will need to be sensitive to how the particular methodologies chosen can elicit different types of data on near misses. Similar to construct validity issues faced in traditional research on capturing behaviour (Stone, 1994) differences are likely to be found between the actual behaviour occurrences of near misses and the memory recall of near miss events. This notion fnotion is supported by the memory recall literature on emotions whereby different types of information have been collected using retrospective surveys versus diary and experienced-sample studies (Bolger et al., 2003; Kahneman et al., 2004). The literature on memory recall in retrospective surveys reveals that events are remembered best when they are unique and particularly salient to the individual (Wagenaar, 1986; Ayhan and Isiksal, 2004). The tendency to remember and over-report negative emotional events is known as the negative retrospection effect and finds support in the literature on emotions (Thomas \& Diener, 1990). Negative informative produces a stronger memory effect and this will affect the ability of study participants to self-report certain events (Scherer et al., 2004).

Furthermore, at the same time, these particular methodologies all rely on varying levels of retrospection, hindsight and require the subject to recall events (Wilhelm et al., 2004). In addition, they also hold the same implicit assumption that emotions are independent of a person 
being a participant in their social life and do not fully address the Heisenberg uncertainty principle that asking individuals to recall particular emotional events is likely to change how they remember the event (Katz, 2004). Therefore, a greater inclusion of naturalistic methods is needed for studying emotional events, in particular, participant observation which "can reveal much that will escape standardized self-reports" (Katz, 2004: 617). Drawing on this literature, we should anticipate that in both quantitative and qualitative studies of near miss phenomena we will observe individuals recalling near misses that are more serious and salient to them (rather than events that are more common and routine). The issue of memory recall also raises epistemological issues which could lead one to conceptualize, for methodological purposes, two types of near miss events: (i) near misses that an individual was, or became, aware of, and (ii) near misses about which the individual was not and never became aware. The second category could involve a researcher observing near misses in a public space, for example, at an intersection watching for near miss car accidents involving pedestrians or cyclists where the drivers (and possibly the cyclists and pedestrians) never become aware of how close they came to being involved in an accident. ${ }^{2}$

\section{How Choices of Data Affect What is Observed}

To date, near miss events are often studied retrospectively with researchers relying on self-report data. There is a growing recognition, however, that there should be a greater inclusion of individuals who have experienced near misses and most likely have not reported them in research strategies. In Table 1, specific methodological tools are listed in reference to their potential to observe everyday behavioural incident near misses versus self-report near misses. When using these research tools, however, the following methodological caveat must be remembered: asking respondents about near miss events will make them think about something that they do not normally think about. Therefore, studying near misses might also, in subtle ways, alter the recognition of and experiences with near miss events. Given that near miss recognition is desirable for learning, and a precursor to primary prevention, researchers should pay special attention to traditional issues of validity when collecting near miss data (Webb et al., 2000).

2. I would like to thank an anonymous reviewer for providing this example. 
Table 1: Methodological tools for capturing near miss data

\begin{tabular}{|c|c|c|}
\hline $\begin{array}{l}\text { Behavioural Incident } \\
\text { Near Misses }\end{array}$ & $\begin{array}{l}\text { Self-Report } \\
\text { Near Misses }\end{array}$ & $\begin{array}{l}\text { Secondary Data Sources } \\
\text { for Near Misses }\end{array}$ \\
\hline $\begin{array}{ll}\text { - } & \text { Participant Observation } \\
\text { - } & \text { Diary Methods }\end{array}$ & $\begin{array}{ll}\text { - } & \text { Surveys/Questionnaires } \\
\text { - } & \text { Interviews (Focus } \\
& \text { Groups) } \\
\text { - } & \text { Life History Calendars }\end{array}$ & $\begin{array}{ll}\text { - } & \text { Clinical studies } \\
\text { - } & \text { Document analysis of } \\
& \text { personal documents } \\
\text { - } & \text { Official documents } \\
\text { - } & \text { Health records } \\
\text { - } & \text { Case law }\end{array}$ \\
\hline
\end{tabular}

\section{Behavioural Incident Near Misses}

A behavioural incident near miss is a frequently occurring type of near miss in a setting and is immediately recorded upon experience in a systematic manner. For example, if a researcher observed or experienced a near miss event in a research setting (such as a slip or trip that almost became an accident) they would then, as soon as possible, record that event as observational data. Ethnographic data is an example of behavioural incident near miss data. The defining feature of a behavioural near miss event is that it is recorded upon experience and is not solely dependent on memory recall.

Behavioural incident near misses are the most frequently occurring types of near misses but remain, at the same time, the most elusive near miss data to collect. The reason for this is illustrated in the previous section on emotions and memory in the recognition of events that 'almost happened'. Altough near misses take place all the time the majority of them are experienced at an unconscious level or in an unreflective habitual manner. However, discussions of near misses heighten sensitivity to behavioural near miss incidents and lead to the possibility of increased recognition of such events. The types of research methods that are best able to answer questions on everyday behavioural incident near misses are those methodologies that do not require the immediate memory recall of research subjects or participants. The following two types of methodologies will be discussed in relation to their potential for capturing behavioural incident near miss data: participant observation and dairy methods.

\section{(i) Participant Observation}

Rather than rely on what people 'say' (i.e., self-report), observational methods allow researchers to capture behaviour in order to see what 
people 'do'. For instance, a worker responding to a questionnaire, vignette or interview "is not subject to the same contingencies that would apply when making routine decisions in the workplace" (Vaughan, 1998: 29). Therefore, seeking to observe how individuals respond to errors that lead to near misses in real time is valuable. In the qualitative tradition, a researcher would spend extended periods of time in a naturalistic setting, taking extensive field notes, with the goal of observing and/or experiencing near miss events peculiar to that setting (Gray, 2002). In near miss research, observational methods represent the most difficult types of studies to conduct when attempting to capture everyday behavioural incident near miss data. The reason is the difficulty of access and the extended periods of time that researchers must stay in the field attempting to observe near misses. However, whenever possible, these types of studies should be done because the insights gained from observation might lead to discoveries of new near misses and new opportunities to decrease potential harms.

\section{(ii) Diary Methods}

In the study of near misses, the diary methodology represents a unique extension of traditional observational techniques. In essence, the diary method provides an alternative form of participant observation in near miss data collection. Here, rather than the researcher collecting the data through observation, it is the subjects/participants themselves who observe and record their own near miss experiences. The diary method is a promising methodological tool given the difficulties of accessing near miss phenomena and is ideal for behavioural incident near misses and everyday routines. An example of near miss data from a diary study can be found in research conducted by Marsh and Kendrick (1999) where they asked parents to record minor injury near misses that occurred to their preschool children. The diary method can be used to observe when it is not possible for researchers to observe themselves.

Furthermore, unlike retrospective methods (i.e., questionnaires and interviews) the diary methodology is less influenced by recall bias. Diaries also serve as a memory aid in recalling everyday events that are easily forgotten (Verbrugge, 1980). The diary method approach can also be used in conjunction with other methodologies, such as in-depth interviews. For instance, when conducting a near miss diary study a researcher may (upon completion of the diaries) conduct in-depth interviews with the informants to clarify the near miss accounts. In addition to combining diary methods with interviews, near miss researchers might instead choose to combine the diary method with a questionnaire in order to 
compare behavioural incident versus self-report near misses. The mixed methods approach, combining diary methods with other methodologies, provides yet another avenue for capturing elusive behavioural incident near misses. However, a limitation of the diary methodology is that they can be expensive and time-consuming for respondents.

\section{Self-Report Near Misses - Primary Data}

A self-report near miss is an account given by a respondent when asked to recall, from memory, a near miss experience. An example of a self-report near miss would be a respondent checking a survey box stating that they have nearly been struck on the head by a flying object at work or stating in an interview that they were almost hit by a moving vehicle. To date, near miss researchers have yet to fully differentiate between self-report near misses and behavioural incident near misses. Generally, self-report near misses capture more sensational near misses and under-estimate the more frequently occurring behavioural incident near misses. However, self-report near misses are the most commonly studied type of near miss information, primarily because self-report near miss data is easier to collect than observational behavioural near miss data (Goldenhar et al., 2003; Powell et al., 2007). Unfortunately though researchers often equate what people say with what people actually do in a particular setting. It must be remembered that there is a difference between what people experience and what they remember.

Retrospective methods (such as questionnaires, interviews, life history calendars) tend to be influenced by recall bias and are more prone to memory decay and the telescoping effect (Harel et al., 1994). While retrospective methods face challenges in memory recall, prospective methods may also change behaviour through reactivity effects (Stone, 1991; Helzer et al., 2002). Given that there is a normalization process in the experience with and recognition of near miss events, near miss consciousness will be heightened when recording them prospectively. Near misses often remain at an unconscious level and forcing an individual to think about them on a daily basis (in a diary) may produce a change in behaviour or a response to near miss events. Future studies collecting self-report near misses should consider the near miss setting (i.e., the context in which near misses are experienced) and incorporate more 'behavioural items' into surveys. In turn, this may assist in eliciting more common everyday near misses. Furthermore, researchers should ask behavioural based questions during qualitative studies. Focus groups (even though they are based on memory-recall) are a 
good option if you cannot observe nor have respondents conduct time diaries (Morgan, 1998).

\section{(i) Focus Groups}

Observation and diaries represent two key types of prospective methodologies in capturing information on mundane day-to-day types of near misses (which often remain at an unconscious level unless triggered). Focus groups, while retrospective in nature, could also assist in the future collection of in-depth near miss information, exploring near miss ideas, and near miss probing. Although the focus group methodology solicits self-report near misses it also has the potential to generate behavioural incident discussions of near misses because of the group interview interaction. During a focus group, individuals will be able to respond to and further develop the near miss narratives of other individuals in the group (if they are all in the same near miss setting). This group dynamic effect has the potential to solicit the more frequently occurring behavioural incident near miss events that might remain silent in a traditional one-on-one interview. In other words, the sharing of near miss experiences by one individual may serve to trigger the memories of group members.

Through the group synergy of sharing near miss stories, the near miss focus group methodology has the potential to reveal not only additional near misses but also to highlight how they are experienced and recognized in a variety of subtle ways. In addition, the near miss focus group methodology put forth here could be used in conjunction with other research methods. For instance, if a researcher conducted a participant observation study and/or used a diary type method to collect behavioural incident near miss data then he/she could use these findings in the context of a focus group to trigger the memory recall of the individuals within the group. Similarly, open-ended interviews could also be used prior to the near miss group discussion which, subsequently, could lead to further near miss discoveries. The focus group method could be used at the beginning of a mixed method study to inform the design of quantitative methods (structured interviews/surveys) or other qualitative techniques (in-depth interviews/diaries). The focus group methodology is a promising tool for the triggering of near miss consciousness. 


\section{Secondary Data Sources for Near Misses}

In addition to the aforementioned strategies of collecting data on everyday behavioural incident and self-report near misses there are a variety of secondary data collection resources for near miss information (i.e., clinical studies and content analysis of personal documents, official documents, health records and case law). In most circumstances this information will contain self-report near miss information. One avenue that has been explored in the medical field is to examine clinical records for health circumstances that serve as a proxy for a near miss event (Geller et al., 2002). This approach to the study of near miss events will be appealing to those researchers who seek clinical case comparison groups. Another interesting form of near miss secondary data stems from official documents and historical records. For example, Diane Vaughan's (1996) historical ethnography of the Challenger Space Shuttle disaster in the United States provided insight into how decision-makers responded to errors, close calls and everyday safety problems. In another example, the inclusion of near miss events in conjunction with evidence of Potemkin villages $^{3}$ led to an exception to the exclusive remedy doctrine in a $\mathrm{Su}-$ preme Court case, thereby allowing a worker to sue their employer for an injury (Burton, 2002). Future secondary analyses of case law and other publicly available secondary data could provide data on different types of sensational near miss events. There is also a wealth of un-tapped near miss information in legal cases involving near miss events in conjunction with psychological harm.

\section{Comparing Self-Report Versus Ethnographic Near Misses}

Different types of methodologies are suited to capture different types of near miss data information, even within the same setting. Although some methods are better suited to answer questions on everyday behavioural incidents, other research instruments are best able to answer questions with self-report near misses. This is illustrated by the following comparison of quantitative and qualitative near miss data collected on the same group of workers in an industrial factory in Ontario, Canada. The qualitative data was collected during an in-depth five-month ethnography of the factory which was followed by a subsequent mail-in survey

3. Potemkin villages constitute the purposeful presentation of fake realities during safety inspections (Gray, 2006; Gray and Silbey, 2014). 
of the same workplace one year later. ${ }^{4}$ The eligible sample population consisted of 328 employees, of which 168 surveys were returned, generating a survey sample rate of 52 percent. The first phase of this study, the ethnography, proved invaluable for it captured everyday near miss events while they were occurring (Gray, 2002). The subsequent selfreport survey provided comparative insights into the memory recall of near misses within the same setting. The differences observed in the two data sets highlighted that memory and emotion play an important role in the collection of near miss data. As shown in Table 2, the two competing methods produced different types of near miss data.

Table 2: Differences in types of near miss data collected on the same population

\begin{tabular}{|c|c|}
\hline $\begin{array}{c}\text { Behavioural Incident Near Misses } \\
\text { (Ethnography) }\end{array}$ & $\begin{array}{c}\text { Self-Report Near Misses } \\
\text { (Survey) }\end{array}$ \\
\hline Subtle \& Routine & Direct \& Dramatic \\
\hline $\begin{array}{c}\text { Trips, Slips } \\
\text { and Falls (TSFs) }\end{array}$ & $\begin{array}{c}\text { Flying Objects, } \\
\text { Moving Vehicles }\end{array}$ \\
\hline
\end{tabular}

The participant observation data revealed that the majority of near misses were more subtle and routine, such as TSFs (trips, slips and falls). TSF near misses were the most frequent type of near miss event observed during the ethnographic study and represent an important prevention focus given their association with high levels of workplace injuries and compensation costs. In Ontario, Canada, accidents caused by TSFs ac-

4. It should be understood that the organization, involved in numerous manufacturing operations, appeared to be an ideal place for workers to report near misses because of union protection and the company's own stated position that safety is a top priority. In addition, the company also had a full-time health and safety representative on staff. It can be argued then that the problems surrounding near misses found at this particular setting would be a conservative account. By illustrating problems with near miss safety in a more progressive organization one is able to state more confidently that similar near misses likely exist elsewhere, and that worse conditions are to be found in less progressive workplaces where safety is not expressed as a top priority and where no union is in place. Therefore, the organization was not an unusual place and the conceptual themes related to the near miss framework should also be discovered, to varying levels and degrees, across public and private near miss settings. 
counted for $18.5 \%$ of all lost time injury claims from 1996 to 2005 (Ontario Workplace Safety and Insurance Board). While the ethnography captured the frequently occurring, and often less visible near misses, the self-report data contained overwhelmingly direct and dramatic near miss events. For example, several workers self-reported on the survey almost being hit by moving vehicles, such as overhead cranes and forklifts.

\footnotetext{
"I heard yelling, so, I turned my head to see what was happening and luckily I turned my head back right away because I was nearly hit in the head by an overhead crane with a bundle of steel attached" (18 year old male student worker).
}

"Fork lift missed me by less than two inches at my machine" (41 year old male worker).

A near miss involving a moving vehicle is serious because if one is 'hit' (instead of just missed) the damage could result in a serious injury or workplace death. The majority of the self-reported near misses involved almost being hit by an object, moving vehicles, overhead cranes, and machines. These types of near misses are often experienced in dramatic fashion triggering stronger negative emotion which, in turn, is associated with increased memory recall. Therefore, it is not surprising that even though they are not the most frequently occurring near misses they represent the most frequently self-reported types of near misses.

The only type of near miss event that was observed at a similar frequency in both the self-report and participant observation data sets was 'almost being hit by an object'. This commonality among the two different data sets suggests that this type of near miss is not only sensational (leading to the triggering of negative emotion and increased memory recall) but also occurs at a high frequency rate inside this particular work setting. This conclusion is further supported when examining actual accidents resulting in injury claims. For example, in Ontario, Canada, between 1996-2005 accidents involving 'contact with objects and equipment' accounted for $25 \%$ of all worker's compensation lost time claims. Among young workers, accidents involving 'contact with objects and equipment' accounted for $39.5 \%$ of all lost time injury claims from 2001 to 2005 (Ontario Workplace Safety and Insurance Board).

During the ethnography, a number of serious near misses involving flying objects were observed and it was discovered that even serious near misses have the potential to become normalized in a setting (Gray, 2006). It was observed that jobs that might lead to being hit by an object (such as standing at the end of a machine line organizing parts) were 
often given to new and young workers (Gray, 2009). This finding lends itself to a partial qualitative explanation for why young workers are injured by 'objects' more frequently than older workers. Also, the intersection of gender and near misses was observed during the ethnography whereby positive responses to near misses (possibly fixing the problem) was more likely to take place if the event occurred to a female, in particular, a younger female summer student. This particular response to near misses appeared to stem from a desire among the mostly older male workers to 'protect' the younger females who all had fathers (or some relative) working in the organization. In contrast, the younger male workers seemed to gain acceptance among the older male workers the more they demonstrated that they did not require help and/or could deal with a near miss event by simply continuing to work and not speaking up about the situation.

While the self report near misses and participant observation data emphasized different types of near misses they also complemented each other and led to further understandings of the overall near miss data set. For instance, the role of 'outsiders' (contract workers temporary in the work setting) contributing to the occurrence of near misses was observed in both data sets. The following two quotes were written on the selfreport survey.

"[My] last near miss was when an OUTSIDER setting up a robot program overrode a safety curtain and he did not grasp the fact [understand] that I was working in an unprotected area" (51 year old male worker).

"A low running crane during shut down was dangerously swinging. As I walked by it swung parallel to me at head level. Outside maintenance was using the crane at the time" (21 year female student worker).

While near misses involving outside contractors was commented upon in the self-report data, a key concept emerged in the qualitative study involving 'outsiders within', such as new and young workers. During the ethnography, it was observed that workers were considered to be dangerous (to themselves and other workers) simply because they were new in the local setting. This ethnographic finding supports the statistical observation that injuries are more likely to take place to employees who are new on a job (Smith and Breslin, 2006). 


\section{Moving Forward with Near Miss Research}

Traditional theoretical explanations (regardless of perspective) tend to share the same commonality: a focus on negative outcomes and events. This paper puts forth a near miss framework that represents a shift away from the dominance of negative outcome research towards studying events that 'almost happened'. By conducting near miss research, one may begin to challenge traditional theories, methods, and policies that are implicitly based on negative outcomes. Near miss events by their very nature are elusive and require sociological imagination in order to capture them. However, by studying the complexities of near miss phenomena we serve to gain a more nuanced understanding of events that actually do happen. Although there are key methodological obstacles to observe when studying near misses, there is enormous potential for increasing our knowledge base on a wide variety of substantive topics.

\section{REFERENCES}

Ayhan, Oztas and Semih Isiksal. 2004. "Memory recall errors in retrospective surveys: A reverse record check study." Quality and Quantity 38(5): 475493.

Barach, Paul and Stephen C. Small. 2000. "Reporting and preventing medical mishaps: Lessons from non-medical near miss reporting systems." British Medical Journal 320(7237): 759-763.

Bolger, Niall, Angela Davis and Eshkol Rafaeli. 2003. Diary methods: Capturing life as it is lived. Annual Review of Psychology 54: 579-616.

Breslin, Curtis and Peter Smith 2006. "Trial by fire: A multivariate examination of the relation between job tenure and work injuries." Occupational and Environmental Medicine 63(1): 27-32.

Burton, John F. 2002. "The intentional injury exception to the exclusive remedy doctrine.” Workers' Compensation Policy Review (July/August) 23-27.

Cohen, Lawrence E. and Marcus Felson. 1979. "Social change and crime rate trends: A routine activity approach." American Sociological Review 44(4): 588-608.

Clarke, Sean P., Joan L. Rockett, Douglas M. Sloane, and Linda H. Aiken. 2002. "Organizational climate, staffing, and safety equipment as predictors of needlestick injuries and near misses in hospital nurses." American Journal of Infection Control 30(4): 207-216.

Collinson, David L. 1999. "Surviving the rigs: Safety and surveillance on North Sea oil installations.” Organization Studies 20 (4): 579-600. 
Conerly, Caroline. 2007. "Strategies to increase reporting of near misses and adverse events." Journal of Nursing Care Quality 22(2): 102-106.

Geller, S.E., D. Rosenberg, S.M. Cox, and S. Kipatrick. 2002. "Defining a conceptual framework for near-miss maternal morbidity." Journal of the American Medical Women's Association 57(3): 135-139.

Goldenhar, Linda M., Larry J. Williams and Naomi G. Swanson. 2003. "Modelling relationships between job stressors and injury and near-miss outcomes for construction labourers." Work \& Stress 17(3): 218-240.

Gray, Garry., Silbey, Susan. 2014. Governing Inside the Organization: Interpreting Regulation and Compliance. American Journal of Sociology 120(1): 96-145.

Gray, Garry. 2011. Constraints to Upholding Workplace Safety Laws and Regulations within Organizations. Revue Droit et Société 77(1): 57-68.

Gray, Garry 2009. The Responsibilization Strategy of Health and Safety: Neoliberalism and the Reconfiguration of Individual Responsibility for Risk. British Journal of Criminology 49(3): 326-42.

Gray, Garry. 2008. Local Safety Cultures of Risk and Regulation: Workplace Safety, Individual Responsibility, and Near Miss Accidents. PhD Dissertation, University of Toronto.

Gray, Garry. 2006. The Regulation of Corporate Violations: Punishment, Compliance, and the Blurring of Responsibility. British Journal of Criminology 46(5): 875-92.

Gray, Garry. 2002. A Socio-legal Ethnography of the Right to Refuse Dangerous Work. Studies in Law, Politics \& Society 24: 133-69.

Harel, Yossi, Mary D. Overpeck, Diane H. Jones, Peter C. Scheidt, Polly E. Bijur, Ann C. Trumble, and John Anderson. 1994. "The effect of recall bias on estimates of annual non-fatal injury rates for children and adolescents." American Journal of Public Health 84(4): 599-605.

Helzer, John E., Gary J. Badger, Gail L. Rose, Joan A Mongeon and John S. Searies. 2002. "Decline in alcohol consumption during two years of daily reporting." Journal of Studies on Alcohol 63(5): 551-558.

Kahneman, Daniel., Alan B. Krueger, David A. Schkade, Norbert Schwarz and Arthur A. Stone. 2004. "A survey method for characterizing daily life experience: The day reconstruction method.” Science 306: 1776-1780.

Kaplan, H.S. 2005. "Getting the right blood to the right patient: The contribution of near-miss event reporting and barrier analysis." Transfusion Clinique et Biologique 12(5): 380-384.

Katz, Jack. 2004. "Everyday lives and extraordinary research methods." Social Science Information 43(4): 609-619.

Laughery, Kenneth R. and Kent P. Vaubel. 1993. "Major and minor injuries at work: Are the circumstances similar or different?" International Journal of Industrial Ergonomics 12: 273-279. 
Lundy, D., Laspina, S., Kaplan, H., Rabin Fastman, B., and Lawlor, E. 2007. Seven Hundred and Fifty-Nine (759) Chances to Learn: A 3-Year Pilot Project to Analyse Transfusion-Related Near-Miss Events in the Republic of Ireland. Vox Sanguinis 92: 233-241.

Marsh, P., and Kendrick, D. 2000. Near Miss and Minor Injury Information: Can it be used to plan and evaluate injury prevention programmes? Accident Analysis and Prevention 32: 345-354.

Morgan, David L. 1998. Planning Focus Groups. Thousand Oaks, CA: Sage Publications.

Parke, J., and Griffiths, M.D. 2004. Gambling Addiction and the Evolution of the Near Miss. Addiction Theory and Research 12: 407-411.

Powell, N.B, Schechtman, K.B., Riley, R.W., Guilleminault, C., Chang, R.P.Y., and Weaver, E.M. 2007. Sleepy Driver Near-Misses May Predict Accident Risks. SLEEP 30 (3): 331-342.

Scherer, K.R., Wranik, T., Sangsue, J., Tran, V., and Scherer, U. 2004. Emotions in Everyday Life: Probability of Occurrence, Risk Factors, Appraisal and Reaction Patterns. Social Science Information 43 (4): 499-570.

Stone, E.F. 1994. Construct Validity Issues in Organizational Behavior Research. In J. Greenberg (Ed), Organizational Behavior: The State of the Science (305-334). Greenwich CT: JAI Press.

Thomas, D.L., and Diener, E. 1990. Memory Accuracy in the Recall of Emotions. Journal of Personality and Social Psychology 59: 291-317.

Watters, J.K., and Biernacki, P. 1989. Targeted Sampling: Options for the Study of Hidden Populations. Social Problems 36 (4): 416-430.

Wagenaar, Willem A. 1986. My Memory: A Study of Autobiographical Memory over Six Years. Cognitive Psychology 18: 225-252.

Webb, Eugene J., Campbell, Donald T., Richard D Schwartz. 2000. Unobtrusive Measures. Thousand Oaks, CA: Sage Publications.

Wilhelm, P., Schoebi, D., Perrez, M. 2004. Freequency Estitmates of Emotions in Everyday Life from a Diary Method's Perspective: A Comment on Scherer et al.'s Survey-study 'Emotions in Everyday Life'. Social Science Information 43 (4): 647-665.

Wright, L., and Van Der Schaff, T. 2004. Accident versus Near Miss Causation: A Critical Review of the Literature, an Empirical Test in the UK Railway Domain, and their Implications for other Sectors. Journal of Hazardous Materials 111: 105-110.

WSIB Ontario. http://www.wsib.on.ca/wsib/wsibsite.nsf/public/Statistics

Van Der Schaff, T.W. 1991. Development of a Near Miss Management System at a Chemical Process Plant. In T.W. Van der Schaff, A.R. Hale, and D.A. Lucas (Eds), Near Miss Reporting as a Safety Tool. Oxford: ButterworthHeinemann. 
Vaughan, Diane. 1998. Rational Choice, Situated Action, and the Social Control of Organizations. Law \& Society Review 32 (1): 23-61.

Vaughan, Diane. 1996. The Challenger Launch Decision: Risky Technology, Culture, and Deviance at NASA. Chicago, University of Chicago Press.

Verbrugge, L.M. 1980. Health Diaries. Medical Care 18 (1): 73-95.

Vincent, C. 1999. Reasons for not Reporting Adverse Events: An Empirical Study. Journal of Evaluation in Clinical Practice 5: 1-9.

Garry Gray is an Associate Professor in the Department of Sociology at the University of Victoria. His research focuses on institutional corruption, behavioural ethics, regulation and compliance, and organizational culture. From 20112015, he was a Research Fellow at the Edmond J. Safra Center for Ethics at Harvard Law School where he conducted research on the social organization of unethical behaviour inside institutions of public trust. From 2009-2011, he was a Research Fellow in the Department of Health Policy and Management at the Harvard School of Public Health, where he researched the influence of organizational culture on medical errors and ethical decision-making inside hospital settings.

Email: gcgray@uvic.ca 
190 (C) Canadian Journal of Sociology/Cahiers canadiens de sociologie 42(3) 2018 